\title{
Assessment of Skeletal and Dental Maturation in Different Facial Types of South Indian Population - A Comparative Study"
}

\author{
Dr. Suresh $\mathrm{M}^{1}$, Dr.Basanagouda C Patil ${ }^{2}$, Dr.Vishwanath C Patil ${ }^{3}$, \\ Dr.Sudha Halkai ${ }^{4}$, Dr.Swathi B ${ }^{5}$, Dr. Abhishek Bansal ${ }^{6}$ \\ ${ }^{I}$ Prof and HOD.Dept of Orthodontics, HKE's Dental College AndHospital, Gulbarga. \\ ${ }^{2}$ Professor, Deptof Orthodontics, HKE's Dental College andHospital, Gulbarga. \\ ${ }^{3}$ Reader, Deptof Orthodontics, HKE's Dental College andHospital, Gulbarga. \\ ${ }^{4}$ Sen. Lecturer, DeptofOrthodontics, HKE's Dental College And Hospital, Gulbarga. \\ ${ }^{5}$ P.G. Student, DeptOf Orthodontics, HKE's Dental College And Hospital, Gulbarga. \\ ${ }^{6}$ Sen. Lecturer, Dept of Orthodontics, Vaidik Dental College AndResearch center, Daman.
}

\begin{abstract}
Aim:To assess the skeletal and dental maturation of different facial types in growing children of south Indian population.

Material and Methods: This study comprised of 60 samples with age group of 9-13 years and divided into 3 groups i.e Average growth pattern (control), Vertical growth pattern and Horizontal growth pattern. Lateral cephalograph, Hand wrist radiograph and Panoramic radiograph of each sample was assessed for skeletal and dental age using CVMI, SMI stages and tooth calcification stages. Chronological age was recorded by their last date of birth .All data in the groups was analyzed by student t test.

Results: Students $t$-test was applied and Statistically significant difference was noted with dental and skeletal ages betweenhorizontal and vertical growth pattern,

Conclusion : Subjects with vertical growth pattern presented a tendency to have earlier dental and skeletal maturation compared to horizontal growth pattern .
\end{abstract}

Keywords: Chronological age, CVMI, Dental age, Skeletal age, SMI.

\section{Introduction}

In preventive and interceptive procedure,knowledge of facial growth velocity and percentage of facial growth remaining is very important for effective growth modification interventions.. It must be based on an assessment of each patient's skeletal maturation and dental maturation. Biological age, skeletal age, bone age and skeletal maturation are nearly synonymous terms used to describe the stage of maturation of an individual . ${ }^{1}$ Because of individual variations in timing, duration and velocity of growth, skeletal age assessment is essential in formulating viable orthodontic treatment plans ${ }^{1 .}$ The timing of craniofacial growth and its relationship to other developmental events presents a particular challenge in subjects exhibiting variations in facial form. ${ }^{8}$

In Literature, Nanda and $\mathrm{Rowe}^{8}$ found timing of the adolescent growth spurt for various facial dimensions in open-bite faces and in deepbite faces. The patterns of dimensional increase in each facial type affect their maturational level, producing different adolescent growth spurt timings. ${ }^{8,9} \mathrm{~A}$ difference in dental maturation in subjects with different vertical facial types was observed in his study. And Jansonet $a{ }^{10}{ }^{10}$ as probably first to investigate the influence of facial type on dental development in subjects of the same chronological age.

Therefore, it is evident from the studies that vertical grower mature earlier than horizontal grower whereas according to Jamrozet $\mathrm{al}^{11}$ there existed no difference between two types of facial growers.

Keeping above points in mind, The relationship between dental, skeletal and chronological age is of great interest indicating an advancement or delay compared to standard growth and also the assessment of growth in different facial patterns is very helpful in diagnostic purpose .

Considering lack of data on variability of dental and skeletal maturation between the different facial types, present study was carried out to establish whether the vertical and horizontal growth patterns influence the rate of dental \& skeletal maturation as compared to normal growth patterns of south Indian population.( Gulbarga district in specific). 


\section{Methodology}

The data for this study has been obtained from the patients who visited the Department of Orthodontics and DentofacialOrthopaedics, H.K.E.S'S.N Dental college and other Dental Institution of Gulbarga .( Gulbarga district in specific )Lateral cephalogram, Hand wrist radiograph and Panoramic radiographs of 60 subjects was obtained between age group of 9-13yrs(as the pre - pubertal growth spurt occurs during this period ) and their gaurdian preferably from parents. The chronological age was recorded according to the patient last date of birth ( as provided by their parents). Subjects were classified according to Different facial growth pattern .(Average, Horizontal and Vertical growers ).It is a Cross-Sectional Study

Angularmeasurements were considered to classify either as having Average, Vertical and Horizontal growth pattern are the SN-GO GN ( Angle between Anterior Cranial Base and Steiner's Mandibular Plane ),NSGN / Y-AXIS ( the Angle between the Anterior Cranial Base and line drawn from point S to GN ) and the FH GO / ME( (Angle between Frankfort Mandibular Plane And Down ‘s Mandibular Plane ).

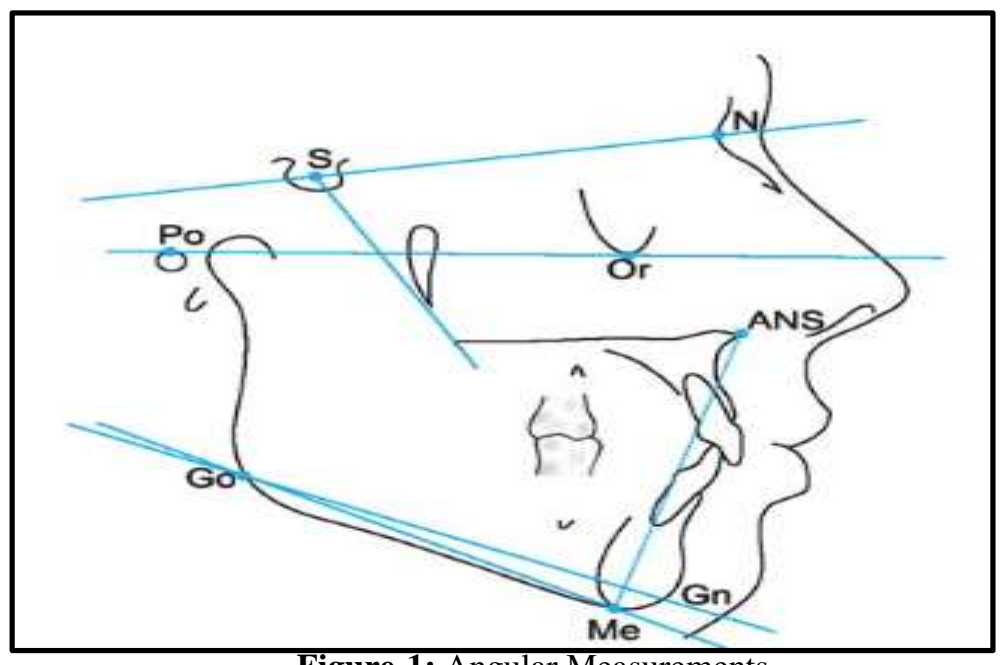

Figure-1: Angular Measurements

Linear Measurements were considered to classify the subjects either as having a short or long vertical growth patterns, based on the values of ANS -ME (Lower Anterior Facial Height) and N-ME ( Total Anterior Facial Height ).The ratio of ANS - ME / N-ME ) lower or equal to $56 \%$ or Higher or equal to $58 \%$ ) .

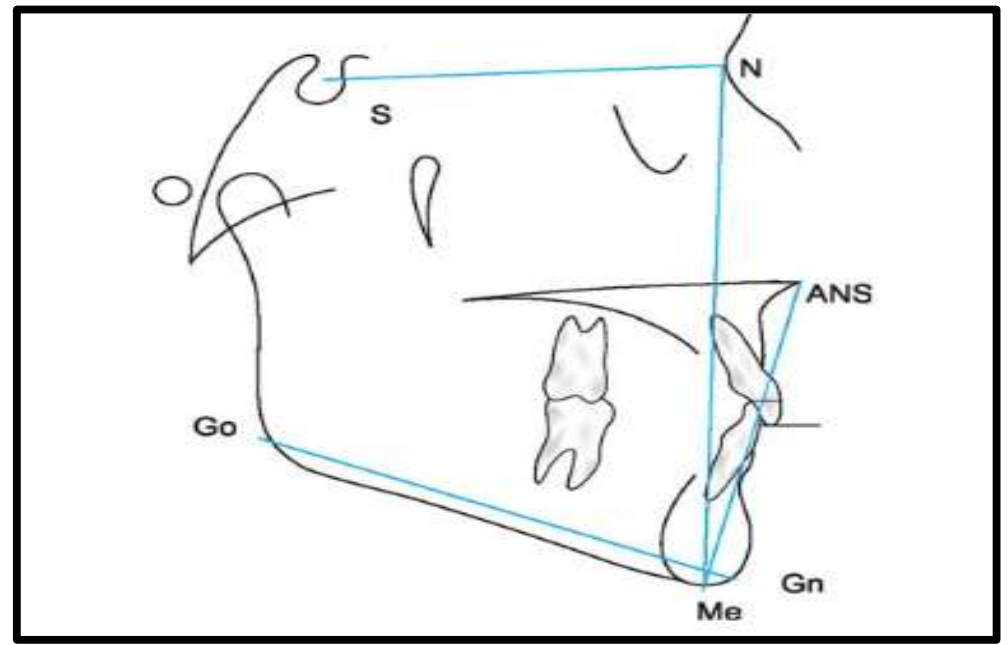

Figure-2: Linear Measurements

Assessment of skeletal maturation using SMIs

To evaluate the maturational patterns of the indicators in the hand wrist, eleven grade system of Fishman (1982) was used. 
1 This system uses only four stages of bone maturation, all found at six anatomical sites located on the thumb, third finger, fifth finger and radius.

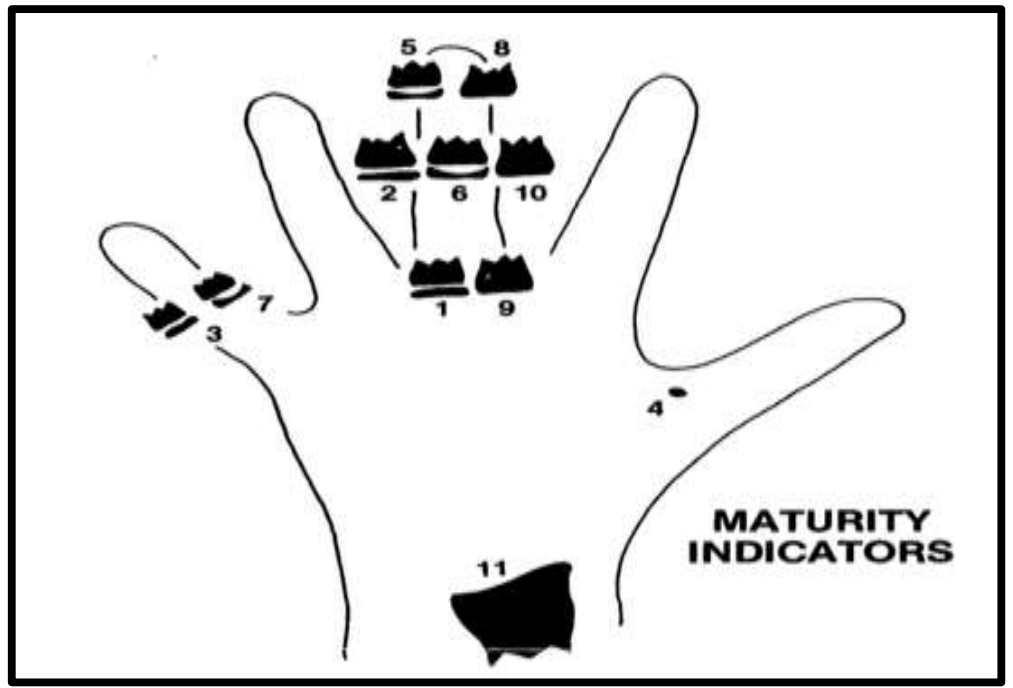

Figure-3: Radiographic Identification of Skeletal maturity indicators

\begin{tabular}{|c|c|c|}
\hline Skeletal maturation indicator & Males age (years) & Female age (years) \\
\hline SMI 1 & 11.0 & 9.0 \\
\hline SMI 2 & 11.7 & 10.6 \\
\hline SMI 3 & 12.1 & 10.9 \\
\hline SMI 4 & 12.3 & 11.2 \\
\hline SMI 5 & 13.0 & 11.6 \\
\hline SMI 6 & 13.8 & 12.0 \\
\hline SMI 7 & 14.4 & 12.3 \\
\hline SMI 8 & 15.1 & 13.1 \\
\hline SMI 9 & 15.5 & 13.9 \\
\hline SMI 10 & 16.4 & 14.8 \\
\hline SMI 11 & 17.4 & 16.1 \\
\hline
\end{tabular}

Age assessment by SMI (years)

Assessment of skeletal maturation using cervical vertebrae

Cervical vertebral development of the sample was evaluated by Hassel and Farman, modification of Lamparski's criteria, which assess maturational changes of the second, third and fourth cervical vertebrae. Farman ${ }^{1}$

Six distinct stages of growth can be related to the skeletal maturity indicator developed by Hassel and

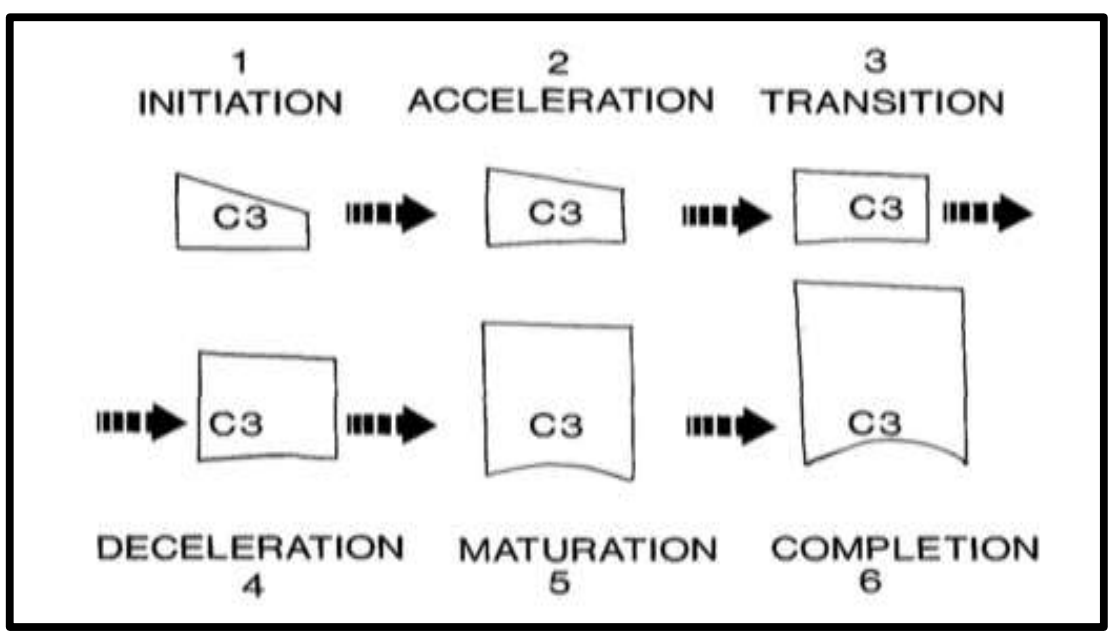

Figure-7: Stages of CVMI 
Age assessment by CVMI (years)

\begin{tabular}{|c|c|c|}
\hline $\begin{array}{c}\text { Cervical vertebrae maturity } \\
\text { indicator }\end{array}$ & Males age (years) & Female age (years) \\
\hline CVMI -1 & 11.6 & 10.4 \\
\hline CVMI-2 & 12.3 & 10.7 \\
\hline CVMI-3 & 13.2 & 11.8 \\
\hline CVMI-4 & 14.2 & 12.8 \\
\hline CVMI-5 & 15.7 & 14.3 \\
\hline CVMI-6 & 17.2 & 16.3 \\
\hline
\end{tabular}

\section{Assessment Of Dental Maturation}

The assessment of dental maturation from the panoramic radiographs was based on the left mandibular teeth and following the method described by Demirjian et al., in which eight stages of calcification from A to $\mathrm{H}$ are described for each tooth.

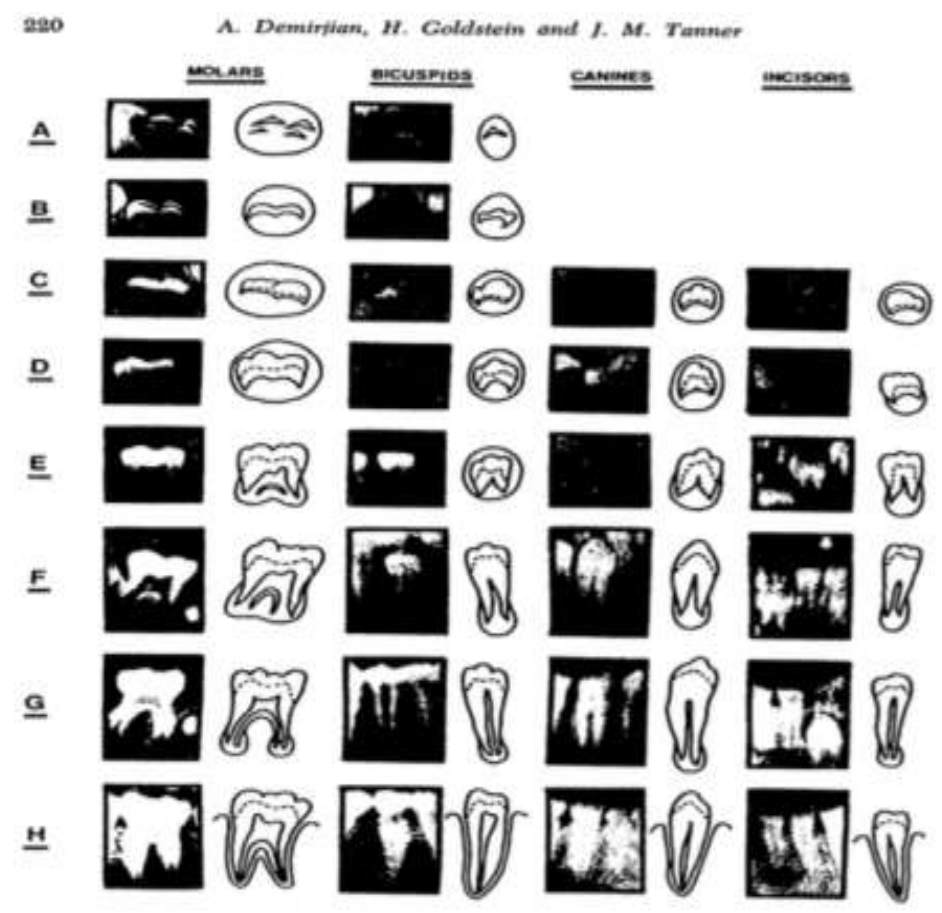

Figure-10: Developmental stages of the permanent dentition.

7 teeth (Mandibular Left Side)

\begin{tabular}{|c|c|c|c|c|c|c|c|c|c|}
\hline \multicolumn{10}{|c|}{ Boys } \\
\hline Tooth & 0 & A & B & $\mathrm{C}$ & $\mathrm{D}$ & $\mathrm{E}$ & $\mathrm{F}$ & $\mathrm{G}$ & $\mathrm{H}$ \\
\hline $\mathrm{M}_{2}$ & 0.0 & 2.1 & 3.5 & 5.9 & 10.1 & 12.5 & 13.2 & 13.6 & 15.4 \\
\hline $\mathrm{M}_{1}$ & & & & 0.0 & 8.0 & 9.6 & 12.3 & 17.0 & 19.3 \\
\hline $\mathrm{PM}_{2}$ & 0.0 & 1.7 & 3.1 & 5.4 & 9.7 & 12.0 & 12.8 & 13.2 & 14.4 \\
\hline $\mathrm{PM}_{1}$ & & & 0.0 & 3.4 & 7.0 & 11.0 & 12.3 & 12.7 & 13.5 \\
\hline $\mathrm{C}$ & & & & 0.0 & 3.5 & 7.9 & 10.0 & 11.0 & 11.9 \\
\hline $\mathrm{I}_{2}$ & & & & 0.0 & 3.2 & 5.2 & 7.8 & 11.7 & 13.7 \\
\hline $\mathrm{I}_{1}$ & & & & & 0.0 & 1.9 & 4.1 & 8.2 & 11.8 \\
\hline \multicolumn{10}{|c|}{ Girls } \\
\hline & & & & & & & & & \\
\hline Tooth & 0 & $\mathrm{~A}$ & $\mathrm{~B}$ & $\mathrm{C}$ & $\mathrm{D}$ & $\mathrm{E}$ & $\mathrm{F}$ & $\mathrm{G}$ & $\mathrm{H}$ \\
\hline $\mathrm{M}_{2}$ & 0.0 & 2.7 & 3.9 & 6.9 & 11.1 & 13.5 & 14.2 & 14.5 & 15.6 \\
\hline $\mathrm{M}_{1}$ & & & & 0.0 & 4.5 & 6.2 & 9.0 & 14.0 & 16.2 \\
\hline $\mathrm{PM}_{2}$ & 0.0 & 1.8 & 3.4 & 6.5 & 10.6 & 12.7 & 13.5 & 13.8 & 14.6 \\
\hline $\mathrm{PM}_{1}$ & & & 0.0 & 3.7 & 7.5 & 11.8 & 13.1 & 13.4 & 14.1 \\
\hline $\mathrm{C}$ & & & & 0.0 & 3.8 & 7.3 & 10.3 & 11.6 & 12.4 \\
\hline $\mathrm{I}_{2}$ & & & & 0.0 & 3.2 & 5.6 & 8.0 & 12.2 & 14.2 \\
\hline $\mathrm{I}_{1}$ & & & & & 0.0 & 2.4 & 5.1 & 9.3 & 12.9 \\
\hline
\end{tabular}

All the samples were evaluated for their respective stages of skeletal and dental maturation as per the methods developed by Fishman ${ }^{2}$ for SMI stages using handwrist radiographs, for CVMI stages using lateral 
cephalograph(Hassel and Farman) ${ }^{1}$, Demirjian ${ }^{7}$ method was used to assess dental age using OPG. All radiographs were evaluated by same operator and later verified by an independent evaluator to determine any inter-operator and intra-operator errors.

\section{Result And Observation}

An unpaired student $t$ test was used to determine among all three groups . To compare, if there was a significant differences between chronological age, dental age and skeletal age of Horizontal, Average and Vertical growers of Male and Female and within each group .Statistically significant difference was noted with dental and skeletal ages between horizontal and vertical group pattern

Table I .Comparision between CA ,Dental age and Skeletal age of Male and Female Horizontal group done using unpaired students $t$-test .

\begin{tabular}{|c|c|c|c|c|c|c|c|c|c|c|c|c|}
\hline & & \multicolumn{4}{|c|}{ sevex. } & \multicolumn{4}{|c|}{ FEALE } & \multirow{3}{*}{ TVALE } & \multirow{3}{*}{ Pvale } & \multirow{3}{*}{ BIALKK } \\
\hline & & \multirow{2}{*}{ MEAY } & \multirow{2}{*}{ S.D } & \multicolumn{2}{|c|}{ C.I } & \multirow{2}{*}{ MEAN } & \multirow{2}{*}{ S.D } & \multicolumn{2}{|c|}{ CI } & & & \\
\hline & & & & H. & tr. & & & ㄴ.. & $\mathrm{UI}$. & & & \\
\hline \multirow[t]{4}{*}{ HORIZONTAL } & $\mathrm{C} \cdot \mathrm{A}$ & 1226 & 0.45 & it.93 & 12.58 & 11.07 & 0.45 & 11.34 & $\mathrm{t1}_{9} .9$ & 1.46 & 0.0764 & Ns \\
\hline & DENTAL & 11.48 & 0.49 & 11.04 & 11.74 & 10.48 & 0.53 & 10.02 & $\begin{array}{r}10.7 \\
8\end{array}$ & 4.06 & 0.0007 & s \\
\hline & $5 \mathrm{Ma}$ & 1100 & 0.35 & 1100 & 12.20 & 10.87 & 0.55. & 10.48 & $\mathrm{n}_{6}, 2$ & 4.50 & 0.00005 & s \\
\hline & CVM & 11.20 & 0.34 & 11.04 & 11.52 & 10.64 & 0.31 & 10.72 & $\mathrm{t1}_{y} \mathrm{t}$ & 2.23 & $0.038 ?$ & $s$ \\
\hline
\end{tabular}

Horizontal group showed significant difference between dental Age and skeletal age parameters of male and female with $\mathrm{p}<0.05$.

Table II.Comparision between CA ,Dental age and Skeletal age of Male and Female Average group done using unpaired students $\mathrm{t}$-test

\begin{tabular}{|c|c|c|c|c|c|c|c|c|c|c|c|c|}
\hline & & \multicolumn{4}{|c|}{ MALE } & \multicolumn{4}{|c|}{ FEMALE } & \multirow{3}{*}{$\stackrel{\text { T }}{\text { VALUE }}$} & \multirow{3}{*}{ P VALUE. } & \multirow{3}{*}{ REMLARK } \\
\hline & & \multirow{2}{*}{ MEAN } & \multirow{2}{*}{ S.D } & \multicolumn{2}{|c|}{ C.I } & \multirow{2}{*}{ MEAN } & \multirow{2}{*}{ S.D } & \multicolumn{2}{|c|}{$\mathrm{Cl}$} & & & \\
\hline & & & & L. & UL. & & & LI. & UL. & & & \\
\hline \multirow{4}{*}{ Average } & $C_{A}$ & 1159 & 1.06 & 10.83 & 12.35 & 11.39 & 1.13 & 10.58 & 1219 & 0.39 & 0.3506 & NS \\
\hline & DENTAL. & $11: 51$ & 0.70 & 11.01 & 12.01 & 11.11 & 0.63 & 10.66 & 11.56 & 1.27 & 0.1101 & NS \\
\hline & SMI & 11.66 & 0.49 & 11.96 & 12.36 & 11.56 & 0.79 & 10.99 & 1213 & 0.32 & 03763 & NS \\
\hline & CUM & 11.66 & 0.45 & 11.33 & 11.98 & 11.46 & 0.40 & 11.17 & 11.75 & 0.99 & 0.1676 & NS \\
\hline
\end{tabular}

Average group (control) showed non significant difference between dental and skeletal age parameters with $\mathrm{p}>0.05$.

Table-III: Comparision between CA, Dental age and Skeletal age of Male and Female Vertical group done using unpaired students $t$-test

\begin{tabular}{|c|c|c|c|c|c|c|c|c|}
\hline & & \multicolumn{2}{|c|}{ MALE } & \multicolumn{2}{|c|}{ FEMALF } & \multirow{2}{*}{$\begin{array}{c}\mathrm{T} \\
\text { VALUE }\end{array}$} & \multirow{2}{*}{$\begin{array}{c}\stackrel{p}{P} \\
\text { VAL.U } \\
E\end{array}$} & \multirow{2}{*}{$\begin{array}{l}\text { REMAR } \\
\text { K }\end{array}$} \\
\hline & & MEA & S.D & MEA & SD & & & \\
\hline \multirow{4}{*}{ Vertical } & C.A & 11.88 & 0.52 & 11.25 & 0.75 & 1.55 & 0.1076 & Ns \\
\hline & DENTAL & 12.53 & 1.11 & 12.00 & 0.95 & 2.12 & 0.0241 & $\mathrm{~s}$ \\
\hline & sMI & 12.67 & 0.77 & 12.08 & 0.81 & 1.44 & 0.1670 & Ns \\
\hline & $\cos$ & 12.06 & 0.25 & 11,52 & 0.28 & 3.99 & 0.0004 & $s$ \\
\hline
\end{tabular}


Vertical group showed significant difference between dental and skeletal age parameters of male and females with $\mathrm{p}<0.05$.

Table -IV Comparsion Between Horizontal And Vertical Group For Male By Student T Test

\begin{tabular}{|c|c|c|c|c|c|c|}
\hline Sex & Age & Groups & Mean & S.D & T value & $\mathrm{P}$ value \\
\hline \multirow[t]{5}{*}{ Male } & CA & & 12.26 & 0.45 & 1.64 & 0.0592 \\
\hline & & VERTICAL & 11.88 & 0.52 & & \\
\hline & Dental age & $\begin{array}{l}\text { HORIZONTAL } \\
\text { VERTICAL }\end{array}$ & $\begin{array}{l}11.40 \\
12.53\end{array}$ & $\begin{array}{l}0.49 \\
1.11\end{array}$ & 2.07 & 0.0265 \\
\hline & CVM & $\begin{array}{l}\text { HORIZONTAL } \\
\text { VERTICAL }\end{array}$ & $\begin{array}{r}11.60 \\
12.67\end{array}$ & $\begin{array}{l}0.60 \\
0.77\end{array}$ & 2.37 & 0.0292 \\
\hline & SMI & $\begin{array}{l}\text { HORIZONTAL } \\
\text { VERTICAL }\end{array}$ & $\begin{array}{r}11.20 \\
12.06 \\
\end{array}$ & $\begin{array}{l}0.20 \\
0.25\end{array}$ & 5.52 & 0.0003 \\
\hline
\end{tabular}

Table V .ComparsionBetween Horizontal And Vertical Group For Female By Student T Test

\begin{tabular}{|c|c|c|c|c|c|c|}
\hline Sex & Age & Groups & Mean & S.D & F value & P value \\
\hline \multirow{4}{*}{ Female } & CA & $\begin{array}{c}\text { HORIZONTAL } \\
\text { VERTICAL }\end{array}$ & $\begin{array}{l}11.67 \\
11.25\end{array}$ & $\begin{array}{l}0.45 \\
0.75\end{array}$ & 1.43 & 0.0849 \\
\hline & $\begin{array}{l}\text { Dental } \\
\text { age }\end{array}$ & $\begin{array}{c}\text { HORIZONTAL } \\
\text { VERTICAL }\end{array}$ & $\begin{array}{l}10.48 \\
12.00\end{array}$ & $\begin{array}{r}0.95 . \\
0.53\end{array}$ & 2.21 & 0.0403 \\
\hline & CVM & $\begin{array}{c}\text { HORIZONTAL } \\
\text { VERTICAL }\end{array}$ & $\begin{array}{l}10.87 \\
12.08\end{array}$ & $\begin{array}{l}0.55 \\
0.81\end{array}$ & 3.70 & 0.0361 \\
\hline & SMI & $\begin{array}{c}\text { HORIZONTAL } \\
\text { VERTICAL }\end{array}$ & $\begin{array}{l}10.64 \\
11.52\end{array}$ & $\begin{array}{l}0.81 \\
0.28\end{array}$ & 4.50 & 0.0003 \\
\hline
\end{tabular}

In Tables IV and V. Comparision between horizontal and vertical group among male and female showed significant difference with $\mathrm{p}<0.05$.

Hence there was an advanced dental age and skeletal age observed for the vertical group, representing earlier dental and skeletal maturation of subjects with vertical growth pattern compared to horizontal growth pattern which showed delayed maturation

\section{Discussion}

The timing of craniofacial growth and its relation to other developmental events presents a particular challenge in individuals exhibiting extreme variation in facial form ${ }^{8}$.Even within same individuals, growth of different facial dimensions varies considerably relative to the circumpubertal growth spurt. There are general factors of skeletal maturity that results in a tendency for an individual to be advanced or delayed ( Tanner1962). The objective of present study was to evaluate and compare the dental age, skeletal age and compare them with the chronological age in both male and female subjects with different facial growth pattern in south Indian population(Gulbarga district in specific) and To assess the dental and skeletal maturation of different facial pattern .

For this study selection of 60 subjects (30 male and 30 female) with different facial patterns, Linear (the ratio of ANS - ME / N-ME ) lower or equal to $56 \%$ or Higher or equal to $58 \%$ ) and Angular ( SN - GO GN, NS- GN . FH -GO ME )cephalometric variables were standardized and the above cephalometric variables were selected for this study as they are commonly used by orthodontist to classify facial patterns. The Result of our study showed statistically significant difference in dental development of subjects with vertical growth pattern and those with horizontal growth pattern. In our study, The male vertical group had a mean chronological age of $11.88 \mathrm{yrs}$; mean dental age of $12.53 \mathrm{yrs}$ and mean skeletal age 12.36yrs; male horizontal group had mean chronological age 12.26yrs, mean dental age 11.48yrs, mean skeletal age 11.40yrs.( Table IV ) .The female vertical group had a mean chronological age of $11.25 \mathrm{yrs}$, mean dental age of 12.00, and mean skeletal age 11.80yrs; female horizontal group had mean chronological age 11.67: mean dental age 10.48 yrs and mean skeletal age 10.25 ( Table V).

Hence it shows, there was advanced dental age and skeletal age observed for the vertical group, representing earlier dental and skeletal maturation of subjects with vertical growth pattern compared to horizontal growth pattern which showed delayed maturation. There was a difference of 1 year between these group. This difference can be considered clinically significant, especially concerning treatment time, which usually lasts 18 to 24 months. Indirectly, additional support is provided to the finding of Shuttleworth (1939), who reported that girls with an early peak height velocity are more advanced in dental emergence . 
The present study showed findings which are comparable to those of Nanda and Rowe ${ }^{8}$,Jansonet $\mathrm{al}^{10}$,Naves et $\mathrm{al}^{21}$ and Gran and leves ${ }^{14}$ Nanda and Rowe ${ }^{8}$ observed that subjects with skeletal open bite and increased LAFH had earlier maturation of craniofacial growth than subjects with skeletal deepbite and reduced LAFH. These two studies have also led to investigations of dental maturation in subjects with different facial growth patterns. Jansonet al ${ }^{10}$ was probably first to investigate the influence of facial type on dental development in subjects of the same chronological age. They showed that skeletal open bite presented a tendency to have an advanced dental maturation in comparison to skeletal deep bite .

Naves et al ${ }^{21}$ compared the maturation stages of permanent teeth in subjects with vertical and horizontal growth pattern and concluded that subjects with vertical growth pattern had earlier dental maturation than horizontal grower.The explanation given by Garn and Leves ${ }^{14}$ for earlier dental maturation of subjects with vertical growth pattern in relation to those having horizontal growth pattern, this is based mainly on intrinsic characteristic of each of the facial types, in addition to genetic aspects. When the mean dental ages observed in this study were compared with the mean chronological ages of the subjects in each group, male and female subjects in vertical group showed a more advanced mean dental age than mean chronological age(Table III).On the other hand, the horizontal group had a more delayed mean dental age and skeletal age compared with mean chronological age. (Table I).

Therefore, the use of chronological age in tables of dental development might misguide the professional if individual growth patterns are not considered. Using chronological age overestimates the dental maturation of subjects with horizontal growth and consequently underestimates their growth potential. The opposite occurs for subjects with vertical growth. (Janson et al) ${ }^{10}$. The skeletal age estimate of male adolescent spurt onset has one third (36\%) the variation of chronological age estimate and is a more accurate indicator of timing of spurts than in chronological age as suggested by Earl o Bergerson ${ }^{15}$.

In present study, Male horizontal and vertical growers shows slightly ahead of female horizontal and vertical growers in dental and skeletal age. The above finding supports theUysal T, Ramolu SI, Basfecti ${ }^{22}$ states $^{2}$ that the appearance of each skeletal stage is consistently earlier in males than in females, At the same time skeletal maturity stage, males had more advanced in tooth calcification.

These difference are suggestive of considerable interregional variation in growth tempos. such difference infer the use of few regionally specific published norms as nationwide standards for the tempos of growth. ( Mappe\& Harris1992) ${ }^{17}$.

Racial \& sexual differences and other less tangible factors such as climate, nutrition, socio-economic levels \& urbanization may influence the rates of physiologic maturity of a child. This renders the chronological age as unreliable indicator of maturational levels. ${ }^{3}$ Bjork (1972) in his study reported that the pattern of facial growth is very strongly correlated with skeletal age than with chronological age, and suggested that certain types of orthodontic treatment coincided with the pubertal growth spurt.

Hence Influence of different facial types on dental and skeletal maturation has been studied and subjects with vertical growth pattern presented a tendency towards an advanced dental age and skeletal age than horizontal growth pattern .

\section{Clinical considerations-}

A clinical implication of this study concerns the ideal period for beginning orthodontic or orthopedic treatment. Patients with a predominantly vertical growth pattern should begin orthodontic therapy earlier than those with a predominantly horizontal growth pattern, because signs of the pubertal growth spurt appear earlier in children with vertical facial growth, ${ }^{9,10}$ and their permanent teeth demonstrate earlier maturation than subjects with horizontal growth patterns, according to our results.

Thus, it is important to observe the patient's growth pattern .so that therapy can start during a suitable period. such as functional and mechanical orthopedic treatment.Therefore, in addition to skeletal age, dental age and co-relation with growth pattern should be considered to correctly time treatment onset.

\section{Conclusion}

On the basis of result obtained from present study the following conclusion were drawn :

1. Dental maturation in vertical and horizontal growing childrens

Individuals with vertical growth pattern showed advanced dental maturation when compared with horizontal growth pattern, which showed delayed dental maturation .

2. Skeletal maturation in vertical and horizontal growing individuals using SMI and CVM

Individuals with vertical growth pattern showed advanced skeletal maturation when compared with horizontal growth pattern, which showed delayed skeletal maturation

Male vertical growers showed slightly ahead of skeletal maturation when compared with female vertical growers 
3 Among horizontal growers male and female, showed slightly delayed dental age and skeletal age when compared with chronological age .

4 Among vertical growers male and female, showed slightly advanced dental age and skeletal age when compared with chronological age .

When considering preventive treatment plan in growing patients, this study permits us to conclude that orthodontic treatment should be started earlier in patient with a vertical growth pattern than those with horizontal growth pattern .

\section{Bibliography}

[1]. Hassel B., Farman A.G. Skeletal maturation evaluation using cervical vertebrae. Am. J. OrthodDentofac. Orthop.1995; $107: 58-66$.

[2]. Fishman L.S. Radiographic evaluation of skeletal maturation. A clinically oriented method based on hand-wrist films. Angle Orthod.1982; 52: 88-112.

[3]. Fishman L.S. Chronological versus skeletal Age, an evaluation of Craniofacial Growth.Angle Orthod.1979; 49:181-189.

[4]. Fishman L.S. Maturation patterns and prediction during adolescent. Angle Orthod.1987; 57:178 -193.

[5]. Lampraski D.G. Skeletal age assessment utilizing cervical vertebrae.1972 Master of Science Thesis.University of Pittsburgh.

[6]. Nolla CM. The development of the permanent teeth.J Dent Child.1960; 27:254-26

[7]. ADemirjian et al ,A new system of dental age assessment, Human Biol, 45, 1973, 211-227.

[8]. SK Nanda, T K Rowe, Circumpubertal growth spurt related to vertical dysplasia, Angle Orthod, 59, 1989, $113-122$.

[9]. S.KNanda. Patterns of vertical growth in the face. Am. J. Orthod 93, 1988,103-16.

[10]. JansonGuilherme, Martins DR, Tavano O. Dental maturation in subjects with extreme facial patterns, Eur J Orthod, 20, 1998,7378.

[11]. Jamroz G MH, Kuijpers -Jagtman AM, Van Hof MA, KatsarosC . Dental maturation in short and long facial types . Is there a difference . Angle Orthod2006, 76-768-72

[12]. Todd T.W. Atlas of skeletal maturation Part I, hand. London, Kimpton 1937.Greulich W. Pyle S.I. Radiographic atlas of skeletal development of hand wrist 1959; Stanford University Press.

[13]. Nanda R.S. The rates of growth of several facial components measured from serial cephalometric roentgenograms. Am. J. Orthod. 1955; 41: 658-673.

[14]. Lewis A.B., Garn S.M. The relationship between tooth formation and other maturational factors.Angle Orthodont.1960; 70-77.

[15]. Earl O Bergerson .the male adolescent facial growth spurt : its prediction and relation to skeletal maturation . Angle Orthod $1972: 42$ : 319 -28.

[16]. Demirjian A., Buschang P.H., Tanguay R., Patterson D.K. Interrelationships among measures of somatic, skeletal, dental and sexual maturity. Am. J. Orthod 1985; 88: 433-438.

[17]. Mappes MS, Harris EF, Behrant RG .Regional difference in tooth and bone development .Am J OrthodDentofacialOrthopaedic $1992.101: 145-51$.

[18]. Baccetti T., Franchi L., Toth L.R., McNamara Jr. J.A. Treatment timing for Twin-block therapy. Am. J. Orthod. Dentofac.Orthop 2000; 118: 159-170.

[19]. FranchiL ,Baccetti T , Mc N amara JA . Mandibular growth as related to cervical vertebral maturation and body height . Am J OrthodDentofacialorthod2000. 335-40

[20]. Profit WR . Treatment timing : Effectiveness and efficiency, treatment timing, orthodontics in four dimension . Craniofacial growth series $2002: 39: 13-24$.

[21]. L.SantosNeves, Comparative study of the maturation of permanent teeth in subjects with vertical and horizontal growth patterns . Am J OrthodDentofacial Orthop, 128, 2005, 619-23.

[22]. Uysal T, Ramoglu S. I, Basciftci F. A, and Sari Z. Chronological age and skeletal maturation of the cervical vertebrae and hand-wrist: Is there a relationship ?. Am. J. Orthod. Dentofac. Orthop, 2006130: 622 - 628.

[23]. Gottimukkla P, Gandikota CS, Challa PS, Perumalla . Assessment of skeletal and dental maturation of short and long face childrens of south indianpopulation. Journal of indian orthodontic society $2012: 148-153$.

[24]. Zachary J, Rolf G Behrent, lyse E, Johnston Jr. The pattern of facial skeletal growth and its relationship to various common indexes of maturation . Am. J. Orthod. Dentofac.Orthop2013:143:845-855.

[25]. Rezwana Begum Mohammed, V. Siva Kalyan, SarithaTircouveluri, GouthamChakravarthy. The reliability of Fishman method of skeletal maturation for age estimation in children of South Indian population .Journal of Natural Science, Biology and Medicine . 2014 